\title{
Fertilizer Subsidy and Rice Productivity in Ghana: A Microeconomic Study
}

\author{
Shaibu Baanni Azumah (Corresponding author) \\ Monitoring and Evaluation Specialist (Solidaridad West Africa). \\ Department of Agricultural and Resource Economics, University for Development \\ Studies, P. O. Box TL 1350. Tamale, Ghana. \\ Tel: +233208381723Ｅ-mail: raszumah1983@gmail.com \\ Abraham Zakaria \\ Department of Agricultural and Resource Economics, University for Development \\ Studies, P. O. Box TL 1350. Tamale, Ghana. \\ Tel: +233 204287512 E-mail: zackabram@yahoo.com
}

Received: Jan. 26, 2019

Accepted: Feb. 18, 2019

Published: Feb. 20, 2019

doi:10.5296/jas.v7i1.14367

URL: https://doi.org/10.5296/jas.v7i1.14367

\begin{abstract}
Across Africa, agricultural productivity continues to decline due to poor soil fertility. Smallholder farmers have less access to fertilizers to improve yields. Past and present governments in Ghana have made some efforts to raise productivity and to deepen the economic and social potentials of the agricultural sector by implementing fertilizer subsidy programs. Using data from 543 smallholder rice farmers in northern Ghana, we estimated both endogenous switching regression and treatment effect models to examine the factors that influenced participation in fertilizer subsidy programs, and rice productivity differences among beneficiary and non-beneficiary farmers. This was to address heterogeneity and biases stemming from unobservable characteristics at farm and farmer levels. Farmers' participation in fertilizer subsidy programs was influenced by age, sex, education, farm size, membership of Farmer-Based Organization (FBO), access to media, knowledge of integrated soil and water conservation (SWC) practices, farm to market distance and herbicides application. Productivity of rice was mainly influenced by age, knowledge of integrated SWC, seed and herbicides usage. The outcomes from the treatment effect model revealed a negatively and significant effect of fertilizer subsidy on rice productivity. It is recommended that ways to improve the effectiveness of the fertilizer subsidy policy and distributional mechanisms to farmers should be given much attention to unlock the agricultural potential of Ghana.
\end{abstract}


Keywords: Endogenous switching regression, Fertilizer subsidy, Ghana, Rice, Treatment effect.

\section{Introduction}

Rice is the next largest food crop second to maize in Ghana, and considered to be one of food security crops. Production in rice sector is dominated by smallholders who rely heavily on rainfed regimes with limited use of fertilizers and other inputs due to high cost. One of the major interventions by the government of Ghana is to provide fertilizers at subsidized prices to smallholder farmers to enhance productivity (MoFA, 2016). Fertilizer plays a crucial role in productivity enhancement. It is one of the components of soil and water conservation (SWC) techniques and supported Latin America and Asia to achieve the green revolution (Ogheneruemu \& Abdul-Hameed, 2017). It is estimated that about 50\% of agricultural productivity and growth is attributed to increased quantity of fertilizer usage (Toenniessenn et al., 2008), which eventually leads to improved incomes and wellbeing for farmers.

In spite of the fact that fertilizer use leads to increased agricultural productivity in Sub-Saharan Africa (SSA), and has been used as a coping strategy for soil erosion control, smallholder farmers are still far behind other developing economies in terms of fertilizer application rates. The average quantity of fertilizer application rate in SSA is said to be low according to Druilhe and Barreiro-Hurlé (2012), and estimated to be about $16 \mathrm{~kg} / \mathrm{ha}$ (Ogheneruemu \& Abdul-Hameed, 2017), compared to $90 \mathrm{~kg} / \mathrm{ha}$ in Middle East and North Africa, $126.6 \mathrm{~kg} / \mathrm{ha}$ in North America, $127.9 \mathrm{~kg} / \mathrm{ha}$ in Latin America and the Caribbean, $158.5 \mathrm{~kg} / \mathrm{ha}$ in South Asia and $344.3 \mathrm{~kg} / \mathrm{ha}$ in East Asia and the Pacific region (World Bank, 2014).

The global food insecurity situation from 2007 to 2008 was a major worry all over the world. Governments reacted to this situation in many different ways. In Ghana, one of the strategies to combat this crisis was the enactment and implementation of the fertilizer subsidy policy in 2008 to stimulate domestic agricultural production (Vondolia et al., 2012). The aim was to increase fertilizer application rates by farmers to shore up productivity, especially for the food security crops such as: maize, rice, soybeans, cowpea, among others.

The fertilizer subsidy program has continued under successive governments in Ghana under different shades of policies. Meanwhile, the average fertilizer application rate still remains very low at about $7 \mathrm{~kg} / \mathrm{ha}$ as against 35kg/ha in Cote d'Ivoire (Benin et al., 2013). Many countries are implementing fertilizer subsidy program in the African continent. For instance, fertilizer was given as free input to farmers in Malawi, while in Ghana it was subsidised to farmers at certain prices. It is estimated that about $30 \%$ of subsidies in Senegal was intended to improve access and use of fertilizers through price reduction (Seck, 2016). The subsidy program in Ghana which commenced in 2008 with a quantity of 43,176 metric tonnes (MT) subsidised and valued at GHC 20,654 million $^{1}$, had increased to about 166,800MT with market

${ }^{1}$ Exchange rate is GHC 1.26, GHC 2.67, GHC 4.22, and GHC 4.97 to US \$ 1.00 respectively for year 2008, 2013, 2016 and 2019. (https://currencies.zone/chart/us-dollar/ghanian-cedi) 
value of GHC 64, 005 million in 2013. In the 2012/2013 production season also, seed was also subsidised to boost certified seeds utilization among smallholder farmers in Ghana.

Fertilizer subsidy for farmers was not available in 2014. In 2015, fertilizer subsidy was reintroduced with a quantity of 89,200 MT, and this cost Ghana an amount of GHC 44, 850 million (MoFA, 2016). The types of fertilizer the subsidy affected were NKP and Urea. By the reintroduction of the fertilizer subsidy program, rice productivity increased from 604 thousand MT to 641 thousand MT at the same period (MoFA, 2016). Regardless of the fact that fertilizer is extremely subsidized by government and its development partners, poor implementation of the program limits the number of farmers who have access to it. Farmers have limited access to fertilizer inputs as a result of low income levels (MoFA, 2011). Meanwhile, MoFA (2015) asserts that fertilizer subsidy programs in Ghana have led to increases in average yields of some major crops including rice. The subsidy programs over the years, have also led to an improvement in the balance of trade by decreasing expenditure on food imports. There is also evidence of increased sales and incomes for fertilizer trading companies as well as increased employment along the entire fertilizer supply chain which includes transport services, retail agents and porters who help to cart the commodity.

Studies have been carried out in some African countries to examine the determinants and constraints of fertilizer subsidy to increase agricultural productivity. In Ghana however, research on fertilizer subsidy programs is limited in scope and in dimension. Also, fertilizer subsidy and rice productivity differences among farmers have not been thoroughly examined, hence the need for this study. This will inform policy makers to design better subsidy programs and to improve the effectiveness of the fertilizer value chain to enhance agricultural productivity.

\section{Methodology}

\subsection{Studied location, Sample Size and Data}

The research was conducted using data from famers in the Northern and Upper East regions of Ghana. The regions are the second and third largest producers of paddy rice in the country, accounting for $68,407.25$ metric tonnes and 114,702.19 metric tonnes per annum respectively (MoFA, 2016). However, the sum of total paddy rice produced annually on average yield, in both regions are very low compared to national yield (MoFA, 2016). The two regions have also been identified as among the poorest in Ghana and yet, the food basket of the country (MoFA, 2016). The vegetation of Northern Ghana is generally covered with grass, shrubs and trees. The diversity in tree cover used to be dense until recent times when the effect of climate change and climate variability has hit hard on the region. The region also has a large land mass area with natural valleys, making it suitable for the cultivation of rice.

In terms of sampling, we employed multistage sampling approach to select the respondents. The two regions were purposively selected in the first stage based on the record achieved in rice production. Through stratification, the rice farmers were grouped into those who benefited from fertilizer subsidy program through the government of Ghana "planting for food and jobs" flagship policy, and those who could not access subsidized fertilizer through 
the program. Through simple random method, 543 farmers were then selected. In all, 62 communities were sampled from ten administrative districts for the study. A semi-structured questionnaire was designed and used to access primary data from the respondents. The interviews were conducted using a face-to-face approach with respondents in their residences to ensure confidentiality and privacy.

\subsection{Econometric Model and Estimation Approach}

The goal of fertilizer subsidy policy is to increase agricultural productivity. Fertilizer subsidy policy increases demand for fertilizer by smallholder farmers and its intensity of application. Nevertheless, the success to fertilizer subsidy depends on whether smallholder farmers have access to fertilizer via fertilizer subsidy policy or not. Fertilizer subsidy helps smallholder farmers to afford fertilizer inputs in both present and future to increase agricultural productivity. The researchers therefore, modelled fertilizer subsidy via an illustration of agricultural technology. Different functional forms are explored to examine the impact of fertilizer subsidy and rice productivity differences among farmers. Three estimation procedures have been outlined by Terza (1998) to address problems in the endogenous dummy explanatory variable models:

1. A two-stage method of moments which is done through Heckman's sample selection approach. By this approach, the first stage is made of a probit equation which estimated for the endogenous dummy dependent variable. In the second stage, a regression model with the multiplicative correction factor by non-linear least squares called Inverse Mills Ratio (IMR) is estimated.

2. By employing a non-linear Weighted Least Squares (WLS) estimation procedure.

3. By employing a Full Information Maximum Likelihood (FIML) Endogenous Switching Regression (ESR) estimation model.

Statistically, FIML endogenous switching regression offers the best efficient estimator which is however subject to distributional assumptions (Vondolia et al., 2012). Furthermore, Monte Carlo simulations similarly show that FIML ESR procedure provides the least standard deviation (Oya, 2005). FIML endogenous switching has the ability to correct selectivity bias and heterogeneity problems. Therefore, the ESR model was employed by this study to examine rice farmers' participation in fertilizer subsidy program and productivity differences among smallholder rice farmers. ESR is a suitable method of estimating the effect of fertilizer subsidy on productivity if only one is interested in the two regimes of farmers (i.e. participants and non-participants).

The decision to participate in fertilizer subsidy is voluntary. Smallholder farmers may self-select into fertilizer subsidy program and this is a potential bias (sampling bias). This makes it difficult in determining the counterfactuals. Beneficiaries of fertilizer subsidy for instance may possess inherent special characteristics that make them systematically different from non-beneficiaries as a result of self-selection. The ESR has the ability to control for observable (i.e. age and sex) and unobservable (e.g. skills and experience) characteristics that might justify for smallholder farmers' propensity to be beneficiary of fertilizer subsidy 
program as well as their productivity.

Unobservable inherent behaviours of smallholders and their farms may affect their decision to participate in the fertilizer subsidy program as well as agricultural productivity. These result in inconsistent estimates of the effect of fertilizer subsidy program on rice productivity. Therefore, accounting for the selectivity bias and heterogeneity problem are overcome by employing a simultaneous equation model (ESR) using FIML as has been done by Di Falco et al. (2010), Anang (2017) and Vondolia et al. (2012).

Like Heckman two stage model, ESR also involves two stages. The first stage to estimate the determinants of fertilizer subsidy using a probit model as outlined by Lokshin and Sajaia (2004). This stage can be illustrated as follows:

$$
\begin{gathered}
F_{i}^{*}=\pi G_{i}=+\mu_{i} \\
F_{i}=\left\{i \text { if } F_{i}^{*}>1 \text { or } 0, \text { Otherwise }\right\}
\end{gathered}
$$

Where $F_{i}^{*}$ is the latent dependent factor for fertilizer subsidy, which is observed via the choice decision to be a beneficiary of fertilizer subsidy program. The observed binary choice decision to be beneficiary of fertilizer subsidy program is given by $F_{i}$, which is equal to 1 for beneficiaries of fertilizer subsidy and 0 for non-beneficiaries. $G_{i}$ is a vector of socio-economic and farm characteristics affecting fertilizer subsidy program, $\pi$ is a vector of unknown parameters which are yet to be estimated. $\mu_{i}$ is a stochastic error term. The variables of $G_{i}$ include age, sex, education, off-farm business, farm size, membership of FBO, access to media, credit, farm to market distance, integrated soil and water conservation (SWC) practices and herbicides.

To control selectivity bias, ESR model was use in the second stage where smallholder farmers face two regimes: beneficiary of fertilizer subsidy, and non-beneficiary. The ESR model helps to derive discrete productivity functions for the two regimes. The two rice productivity models are stated as follows:

$$
\begin{aligned}
& \text { Regime } 1: y_{1 i}=x_{1 i} \beta_{1}+\varepsilon_{1 i}, \quad \text { if } F_{i}=1 \\
& \text { Regime } 2: y_{2 i}=x_{2 i} \beta_{2}+\varepsilon_{2 i}, \quad \text { if } F_{1}=0
\end{aligned}
$$

Here, $y_{1 i}$ and $y_{2 i}$ are the dependent variables (log of rice yield) in the continuous productivity function for beneficiaries and non-beneficiaries of fertilizer subsidy respectively; 
$x_{1 i}$ and $x_{2 i}$ represent vectors of exogenous variables, while $\beta_{1}$ and $\beta_{2}$ are vectors of parameters; and $\varepsilon_{1 i}$ and $\varepsilon_{2 i}$ are random stochastic terms. To solve the problem of selectivity bias, the ESR method count on combined normality of the error terms in the binary fertilizer subsidy and rice productivity functions. The error terms $\mu_{i}, \varepsilon_{1 i}$ and $\varepsilon_{2 i}$, are said to have a trivariate normal distribution with zero mean and a covariance matrix which can be stated as:

$$
\operatorname{cov}\left(u_{i,}, \varepsilon_{1 i}, \varepsilon_{2 i}\right)=\Omega=\left[\begin{array}{ccc}
\sigma_{u}^{2} & \sigma_{1 u} & \sigma_{2 u} \\
\sigma_{1 u} & \sigma_{1}^{2} & \sigma_{12} \\
\sigma_{2 u} & \sigma_{12} & \sigma_{2}^{2}
\end{array}\right]
$$

where $\sigma_{u}^{2}$ represents the variance of the disturbance term $u_{i}$ in the selection/probit model in equation $1 ; \sigma_{1}^{2}$ and $\sigma_{2}^{2}$ represent variances of the stochastic terms in the productivity equations; $\sigma_{1 u}$ is covariance of $u_{i}$ and $\varepsilon_{1 i} ; \sigma_{2 i}$ is covariance of $u_{i}$ and $\varepsilon_{2 i}$. The covariance between $\varepsilon_{1 i}$ and $\varepsilon_{2 i}$ is undefined, since $y_{1 i}$ and $y_{2 i}$ cannot be observed concurrently.

According to Lokshin and Sajaia (2004) an efficient and effective way to estimate ESR models is by making good use of FIML estimation technique. This technique concurrently estimates the selection equation and the productivity functions to provide consistent standard errors. According to Lokshin and Sajaia (2004), the ESR model is recognized by constructing non-linear functions.

To achieve the goal of this study, the FIML estimates of the parameters of the ESR model was used by employing the Stata command movestay, which provided consistent estimates. Identification of the model is very relevant, hence at least one independent variable in the first-stage probit model is not included in the substantive productivity model as suggested by Maddala (1983). In addition, it requires that for using ESR model, there is the need to have an instrument(s) that must have a direct effect on the fertilizer subsidy, but not on the outcome variable (rice productivity). The study used farm to market distance as an instrument and as the identification restriction. This is in support of findings in literature that closeness to subsidy programs increases participation, but does not have direct impact on productivity (Vondolia $e t$ al., 2012; Sinyolo et al., 2014).

\subsection{Conditional Expectations Treatment, Heterogeneity and Heckman Treatment Effects}

ESR model helps to compare the expected rice output of farmers who benefited from the fertilizer subsidy program:

a. To that of farmers who did not. 


\section{Macrothink}

b. The model also helps us to examine the expected rice output in the counterfactual hypothetical circumstances.

c. The model also solves the scenario of beneficiary farmer having not benefited, and

d. The case of non-beneficiary famers having benefited.

The conditional expectations for rice output in the four circumstances are summarised in equation 6a-6d and further elaborated in Table 1.

$$
\begin{gathered}
E\left(y_{1 i} \mid B_{i}=1\right)=X_{1 i} \beta_{1}+\sigma_{1 k} \pi_{1 i} \\
E\left(y_{2 i} \mid B_{i}=0\right)=X_{2 i} \beta_{1}+\sigma_{2 k} \pi_{2 i} \\
E\left(y_{1 i} \mid B_{i}=1\right)=X_{1 i} \beta_{2}+\sigma_{2 k} \pi_{1 i} \\
E\left(y_{1 i} \mid B_{i}=1\right)=X_{2 i} \beta_{1}+\sigma_{1 k} \pi_{2 i}
\end{gathered}
$$

Table 1. Conditional expectations, treatment and heterogeneity effects

\begin{tabular}{lccc}
\hline \multirow{2}{*}{ Subsample } & \multicolumn{2}{c}{ Decision Stage } & \\
\cline { 2 - 3 } Beneficiary & To benefit & Not to benefit & Treatment effects \\
(i) $E\left(y_{1 i} \mid B_{i}=1\right)$ & (iii) $) E\left(y_{2 i} \mid B_{i}=1\right)$ & TT \\
Non-beneficiary & (iv) $E\left(y_{1 i} \mid B_{i}=0\right)$ & (ii) $) E\left(y_{2 i} \mid B_{i}=0\right)$ & TU \\
\hline Heterogeneity effects & $\mathrm{BH}_{1}$ & $\mathrm{BH}_{0}$ & TH \\
\hline
\end{tabular}

Notes: (i) and (ii) characterize observed expected outputs. (iii) and (iv) represent the expected outputs of counterfactual.

$B_{i}=1$ if a farmer benefited from the fertilizer subsidy program, $B_{i}=0$ if otherwise. $Y_{1 i}$ is quantity of rice produced by beneficiary farmer. $Y_{2 i}$ is quantity of rice produced by a non-beneficiary farmer. $T T$ is the effect of the treatment (i.e., fertilizer subsidy) on the treated (i.e., farmers that benefited). $T U$ is the effect of the treatment (i.e., fertilizer subsidy) on the untreated (i.e., farmers who did not benefit). $B H_{i}$ is the effect of base heterogeneity for farmers who benefited $(i=1)$, and those who did not benefit $(i=0) . T H=(T T-T U)$, i.e. the transitional heterogeneity.

States (i) and (ii) along the leading diagonal of Table (1) represent the actual expectations observed in the sampled farmers. States (iii) and (iv) form the minor diagonal which 
represents the counterfactual expected outcomes. The difference between (i) and (iii) is the effect of the treatment on treated (TT). By Heckman et al. (2001), the TT can be express as:

$$
T T=E\left(y_{1 i} \mid A_{i}=1\right)-E\left(y_{2 i} \mid A_{1}=1\right)=X_{1 i}\left(\beta_{1}-\beta_{2}\right)+\left(\sigma_{1 k}-\sigma_{2 k}\right) \pi_{1 i}
$$

The equation 7 shows the effect of fertilizer subsidy on the rice output of the farmers that actually benefited from the fertilizer subsidy program. Likewise, the effect of the treatment on the untreated (TU) for the farmers that actually did not benefit from the fertilizer subsidy represents the gap between (iv) and (ii) presented mathematically as:

$$
T U=E\left(y_{1 i} \mid A_{i}=0\right)-E\left(y_{2 i} \mid A_{1}=0\right)=X_{2 i}\left(\beta_{1}-\beta_{2}\right)+\left(\sigma_{1 k}-\sigma_{2 k}\right) \pi_{2 i}
$$

The expected outcomes shown by (6a)-(6d) can be used to compute the heterogeneity effects in the sample. For instance, farmers who benefited from the program may have produced more rice output compared to farmers who did not benefit irrespective of the fact that they decided to benefit, but because of unobservable qualities such as their innate ability and skills. By adjusting ourselves to Carter and Milon (2005), "the effect of base heterogeneity" can be defined by the group of farmers who decided to benefit as the difference between state (i) and (iv).

$$
H B 1=E\left(y_{1 i} \mid A_{i}=1\right)-E\left(y_{1 i} \mid A_{1}=0\right)=\left(X_{1}-X_{2}\right) \beta_{1}+\sigma_{1 k}\left(\pi_{1 i}-\pi_{2 i}\right)
$$

Also, for the group of farmers who decided not to benefit, "the effect of base heterogeneity" is the difference between state (iii) and (ii).

$$
H B 2=E\left(y_{2 i} \mid A_{i}=1\right)-E\left(y_{2 i} \mid A_{1}=0\right)=\left(X_{1}-X_{2}\right) \beta_{2}+\sigma_{2 k}\left(\pi_{1 i}-\pi_{2 i}\right)
$$

The researchers investigate the "transitional heterogeneity" (TH). This is the effect of benefiting from the fertilizer subsidy, which is greater or lesser for the farmers that actually benefited from fertilizer subsidy or for the farmers who actually did not benefit in the counterfactual case that they did benefit. This is the difference between equations (7) and (8) (i.e., (TT) and (TU)).

The limitation of ERS model is that it does not measure the direct effect of fertilizer subsidy on the output of rice, and also fails to cater for selectivity bias. For these reasons, Heckman treatment effect model was used to measure the pure effect of fertilizer subsidy on output as well as correct for selectivity bias.

The orthodox method would have been to estimate a probit equation for the first stage of the objective, and incorporate the dependent variable into the ordinary least square (OLS) function for the substantive equation (stage two). However, Heckman (1974) noted that this could cause a big problem since the results could be bias and would also lead to inconsistent estimates. To overcome this challenge, we followed the Heckman's (1976) two-stage technique (equivalent to treatment effect). This involved an iteration process which generated 


\section{Macrothink

a new variable called Inverse Mills Ratio (IMR) or hazard lambda, after estimating the selection equation (i.e. the determinants of fertilizer subsidy). The new variable is then added as another variable in the second stage. This new variable measures the effect of fertilizer subsidy program on output. Following Greene (1993), mathematical expression of this model can be presented as:

$$
y_{i}=X_{i}^{\prime} \beta+\pi I_{i}+u_{1 i}
$$

$y$ is rice output, $X_{i}^{\prime}$ are exogenous variables which determine rice output, $I_{i}$ is fertilizer subsidy which takes the value (1) if a rice farmer benefited and (0) if the farmer did not benefit from the subsidy program. $u_{1 i}$ is a two sided error term which has $N\left(0, \sigma_{v}^{2}\right)$. $\beta$ and $\pi$ are parameters to be estimated.

According to Maddala (1983), this does not produce adequate result since $I_{i}$ is endogenously determined. Hence, the selection equation (i.e. $I_{i}$ ) is first of all estimated as it illustrated below:

$$
I^{*}=K_{i}^{\prime} \gamma+u_{2 i}
$$

where $K_{i}^{\prime}$ is a set of exogenous covariates that is influence the selection variable $I_{i} . \quad \gamma$ is a parameter to be estimated. $u_{2 i}$ is a two-sided stochastic or error term with $N\left(0, \sigma_{v}^{2}\right)$.

Simply estimating the substantive equation is not possible without first estimating the probit equation since the decision into $I_{i}$ may be determined by unobservable characteristics like inner ability and innovativeness of the part of farmers (Zakaria et al., 2016 and Azumah et al., 2016) which have the tendency to affect output. The implication is that the two error terms (both in the selection and output equations) are correlated, leading to biased estimates of $\beta$ and $\pi$. Therefore, if we assume $u_{1 i}$ and $u_{2 i}$ hold, then the error terms have a joint normal distribution expressed as:

$$
\left[\begin{array}{l}
u_{1 i} \\
u_{2 i}
\end{array}\right] \approx N\left(\left[\begin{array}{l}
0 \\
0
\end{array}\right],\left[\begin{array}{cc}
1 & \rho \\
\rho & \sigma^{2}
\end{array}\right]\right) .
$$

With this expression, the expected rice output of beneficiaries in equation 1 , can be transformed as: 


$$
E\left(X_{i} \mid I_{i}=1\right)=K_{i} \gamma+\pi+E\left(u_{2 i} \mid I_{i}=1\right)=K_{i} \gamma+\pi+\rho \sigma \lambda_{i}
$$

Where IMR:

$$
\left(\lambda_{i}\right)=\frac{\phi\left(-K_{i}^{\prime} \gamma\right)}{1-\Phi\left(-K_{i}^{\prime} \gamma\right)}
$$

Maddala (1983) explained that when rice output of both fertilizer subsidy beneficiaries and non-beneficiaries are considered, equation 11 can be re-expressed as:

$$
Y_{i}=K^{\prime}\left(\Phi_{i} X_{i}\right)+\pi^{\prime}\left(\Phi_{i} I_{i}\right)+\delta \Phi_{i}+e_{2 i} \text { where } \quad \Phi_{i}=\Phi\left(K_{i}^{\prime} Y\right)
$$

\subsection{Statistical Analyses}

This section discusses various statistical approaches that were employed for this study, to complement the econometric and estimation techniques discussed in sections 2.2 and 2.3. We employed $t$-test (see Table 2) to determine statistically significant differences in observed variables between fertilizer subsidy program participants and non-participants. $T$-test is used as a hypothesis testing tool, which allows testing of an assumption applicable to a population. The $t$-test looked at the $t$-statistic, the $t$-distribution values and the degrees of freedom to determine the probability of difference between fertilizer subsidy program participants and non-participants. The significance level for a given hypothesis test was a value for which a $P$-value less than or equal to, is considered statistically significant. Typical values for statistical significance are $0.1,0.05$, and 0.01 . These values correspond to the probability of observing such an extreme value by chance.

To determine the factors accounting for participation in fertilizer subsidy programs, we first performed Wald test of independence for model selection (see Table 3). The Wald test of independence was statistically significant at $1 \%$, indorsing the sample separation. This also means that the Endogenous Switching Regression (ESR) model had a good fit with its explanatory variables, justifying the use of the model. The coefficient of correlations (Rho_1) and $(\mathrm{Rh} 0)$ between the two equations (fertilizer subsidy and rice output) were also estimated to be positive and statistically significant at $1 \%$. The implication is that benefiting from the fertilizer subsidy program was a personal decision which is determined by observable and unobservable characteristics of farmers.

The coefficient of the Inverse Mills Ratio (IMR), also known as the hazard lambda, $(\lambda)$ which test the presence of selectivity bias was also computed. This was statistically significant at $1 \%$, confirming selectivity bias in the sample (see Table 3 ). This was corrected for by the treatment effect modelling. In addition, the finding also implies that there were unobservable farmer and farm attributes which determined the likelihood of participation in the fertilizer subsidy program and rice output at the same time. 


\section{Results and Discussions}

\subsection{Profile of Sampled Farmers}

Table (2) presents the summary statistics of the sampled rice farmers. The results indicated significant differences (at $1 \%$ level) in rice output between beneficiary and non-beneficiary of fertilizer subsidy program. Beneficiary of fertilizer subsidy had about 12 bag $(1032 \mathrm{Kg}){ }^{2}$ less of output compared to their counterpart non-beneficiaries. All the other variables were found to be statistically significant at $1 \%$ for both beneficiary and non-beneficiary groups, except farm size, family labour and seed. Farmers who benefited from the fertilizer subsidy program were relatively older. With respect to sex, there were more males in both subsidy (89\%) and non-subsidy $(75 \%)$ groups. Beneficiaries of fertilizer subsidy program were found to have spent fewer years in formal education (3.03 years) compared to their counterpart non-beneficiaries (5.53 years).

Farmers who benefited from fertilizer subsidy program travelled less distance from their farm to market centres compared to their counterparts who did not benefit. We assume that farmers whose farms are farther away from the fertilizer distribution points (like market centres) have less privilege to access information regarding the fertilizer subsidy program and thus, less likely to benefit from the program. Extension service plays a great role for circulation of agricultural policies to rural farm households. However, our findings showed that non-beneficiaries of the subsidy program received more extension visits compared to those who benefited from the social intervention. The non-beneficiary farmers could have received information about the program, but lacked access to it due to farm or home distance to fertilizer market outlets or due to market distortions.

Table 2. Description of demographic and socioeconomic characteristics of sampled farmers

\begin{tabular}{|c|c|c|c|c|}
\hline Variable description & Subsidy & Non-subsidy & $\begin{array}{c}\text { Mean } \\
\text { difference }\end{array}$ & t-test \\
\hline Age of respondent (years) & 39.83 & 36.53 & $-3.30 * * *$ & -3.56 \\
\hline $\operatorname{Sex}(1=$ male, $0=$ female $)$ & 0.89 & 0.75 & $-0.14 * * *$ & -4.26 \\
\hline Membership to FBO $(1=$ yes, $0=$ No $)$ & 0.53 & 0.79 & $0.26 * * *$ & 6.3 \\
\hline Extension visit (number of times ) & 2.65 & 4.5 & $1.85 * * *$ & 4.02 \\
\hline Access to media $(1=$ Yes, $0=$ No $)$ & 0.96 & 0.47 & $-0.49 * * *$ & -15.79 \\
\hline Farm size ( acre) & 2.22 & 2.71 & 0.49 & 1.56 \\
\hline Farm to market distance & 7.43 & 5.33 & $-2.10 * * *$ & -4.85 \\
\hline Off-farm activities $(1=$ Yes, $0=$ No) & 0.31 & 0.19 & $-0.13 * * *$ & -3.29 \\
\hline Family labour ( number of people) & 4.59 & 3.92 & -0.67 & -1.142 \\
\hline Seed (in $\mathrm{kg}$ ) & 13.95 & 11.52 & -2.43 & -0.71 \\
\hline Adopt integrated SWC $(1=$ Yes, $0=$ No $)$ & 0.61 & 0.36 & $-0.25 * * *$ & -6 \\
\hline Application of herbicides $(1=$ Yes, $0=$ No) & 0.98 & 0.88 & $-0.10 * * *$ & -4.91 \\
\hline Education (years spent in formal education) & 3.03 & 5.53 & $2.50 * * *$ & 5.75 \\
\hline Rice output ( bags) & 26.31 & 38.37 & $12.06 * * *$ & 2.95 \\
\hline
\end{tabular}

*** Significant at $1 \%$.

Source: field data, 2018

$\overline{{ }^{2} \text { A standard bag of rice in the study area weighs approximately } 86 \mathrm{~kg}}$ 
3.2 Rice Productivity Difference Among Beneficiaries and Non-Beneficiaries of the Program

Table (3) presents the results of the Heckman treatment effect (two-stage estimator) and the ESR models. The Heckman treatment effect model corrected for selectivity bias as well as endogeneity effect, and measured the direct impact of the program on the output of rice farmers. Meanwhile, the ESR corrected endogeneity problem and also estimated the factors that account for output among the two regimes of farmers (i.e. fertilizer subsidy beneficiaries and non-beneficiaries). Column 1 denotes the estimated coefficients of output equation in the treatment effect model. Columns 3 and 4 denote the endogenous switching in the rice output functions. While column 2 denotes the selection equation in ESR model. The results of the probit equation in the Heckman treatment effect model (i.e. the determinants of participation in fertilizer subsidy program) are not discussed in this paper since they were similar to the results of the selection equation in the ESR model. ESR model presents the results of both the determinants of participation in fertilizer subsidy program as well as determinants of output for both subsidy and non-subsidy beneficiaries.

\subsubsection{Determinants of Participation in Fertilizer Subsidy Program}

The results of the selection equation in the ESR showed that all the modelled variables were statistically significant but with differing influence on farmers' decision to participate in fertilizer subsidy program. The positive and significant relationship between age and participation meant that older farmers were more likely to have benefited or participated in the fertilizer subsidy program. This result is corroborating with Chirwa et al. (2011), and Imoru and Ayamga (2015), but in contrary with the findings of Martey et al. (2013), and Ragasa and Chapoto (2017).

Sex had positive and significant effect on participation in fertilizer subsidy program, suggesting that male farmers had higher probability of benefiting or participating in fertilizer subsidy program as compared to female farmers. The finding is not surprising as male farmers dominate in rice production in the study area. Male farmers are also more resource endowed, granting them more access to farm inputs. This finding is consistent with Chibwana et al. (2010), and Chirwa et al. (2011), who found male household heads to have higher probability of accessing farm inputs with a coupon package.

Also, education was significant and had an inverse relationship with participation in fertilizer subsidy program. This means that farmers with no or less educational level had greater probability of participating in the fertilizer subsidy program. The coefficient of distance from farm to market was found to be significant and had positive effect on fertilizer subsidy program. This means that less distance from farm to market centres increases the probability of farmers to benefit/participate in subsidy program. This result agrees with Imoru and Ayamga (2015), but in contrary with Zhou et al. (2010) who found that farm distance to market have negative effect on intensity of fertiliser usage.

The number of years of membership in a farmer-based organisation (FBO) also had significant and positive effect on participation. The number of years a farmer spent in an FBO make him/her have access to effective networks. By networking, the farmers could have 
access to information about improved production techniques, farm inputs and market information. Ricker-Gilbert and Jayne (2008) and Liverpool-Tasie (2012) opined that social networks increases farmer's probability of participating or benefiting from inputs subsidy programs. They explained that as the number of years of farmer's membership in an FBO increases their probability to access farm input via subsidy increases.

The coefficient of access to mass media was also positive and statistically significant. Meaning that farmers who have fertilizer subsidy information via mass media (radio and TV) benefited from the fertilizer subsidy program more than their counterparts with less information. Mass media like radio and TV play a great role making information available to farmers on farm inputs subsidy programs (Azumah et al., 2018). According to Nonvide (2018), both input and output markets information could be accessed by farmers through the media. Hence, mass media have the potential to increase usage and adoption of agricultural innovations as well as price information of farm inputs and output.

We found the coefficient of farm size to have significant and negative effect on fertilizer subsidy program. This is in agreement with the finding of Vondolia et al. (2012), but in contrary with Ogheneruemu and Abdul-Hameed (2017). The result means that farmers with small farm sizes had a high opportunity to benefit from fertilizer subsidy program. According to MoFA (2017), farmers under fertilizer subsidy policy with farm sizes above two hectares were not qualified to benefit from the program.

Furthermore, off-farm business had significant and positive effect on fertilizer subsidy, corroborating with Ogheneruemu and Abdul-Hameed (2017). This means that farmers who had off-farm businesses had higher probabilities of participating in fertilizer subsidy program. Off-farm employment provides extra income to farmers which could be used to procure farm inputs. Under the present Ghana fertilizer subsidy program, beneficiary farmers are required to pay upfront, $50 \%$ of the total cost of the fertilizer and other inputs such as improved seed. Farmers who are into off-farm businesses may have the money to meet this cost in order to access the fertilizers.

Adoption of integrated soil and water conservation (SWC) practice was also found to have positive effect on participation in fertilizer subsidy program, implying that a farmer who adopted integrated SWC practices have access and benefits from the subsidy program. Surprisingly, the frequency of extension visits received was found to have negative and significant relationship with participation in the program. Meaning that farmers who had more extension visits within the period had a higher tendency of not participating in the fertilizer subsidy program. The information about fertilizer subsidy program is easily spread to the farmers by the extension agents. Therefore, farmers who received more extension visits within the past 12 months were supposed to have a higher likelihood of understanding and participation in the subsidy program and vice visa. This study could not however, establish the reasons for this diverging finding.

\subsubsection{Determinants of Rice Output Among Farmers}

The primary objective of this study was to examine the effect of fertilizer subsidy program on 
output of rice farmers. Treatment effect model was used to measure the real effect of fertilizer subsidy on output (see Table 3, column 1). This section discusses the results of the substantive estimation (eq. 11).

From the results, the coefficient of fertilizer subsidy program is negative in relation to rice output. This means that farmer participation in subsidy programs did not contribute to an increase in the output of rice per se. One of the contributory factors of this finding is that the fertilizer subsidy program in the 2016/2017 production season in Ghana was designed to favour farmers who cultivated less than two hectares, limiting participation of farmers who had larger farm sizes. However, during the data collection, it was realized that farmers who had larger farmer sizes acquired the fertilizer via the smallholder farmers that had access to the fertilizer subsidy program. Thus, farmers with smaller farm size purchased the fertilizer at less prices via fertilizer subsidy program and resold it to farmers who had larger farms with the aim of making profit. This contributed to increase quantities of fertilizer applied by non-beneficiaries of the fertilizer subsidy program, hence, increased the output of rice for that regime of farmers and vice visa. Some farmers also asserted that fertilizers supplied by the subsidy program were poor in quality. Therefore, some financially resourced farmers refused to participate in the program, but resorted to buying inputs from commercial sources. Other covariates that contributed positively and significantly to output were farmers' age, sex, farm size, duration of membership in FBO, adoption of integrated SWC practices and family labour. However, frequency of extension visits had negative association with output. From Table 3, ceteris paribus, an increase in a farmer's age by one year will lead to an increase in rice output by $1.4 \%$. The youthful age of farmers also aided in the adoption of labour-intensive agricultural innovation which also contributed to increase output. Also, sex was found to be positive and statistically significant at $5 \%$ with a coefficient of 0.233 . This means that output of male farmers was $23.3 \%$ better than their female counterparts. The results from Table (3) also revealed that a $100 \%$ increase in farm size resulted in a $10.8 \%$ increase in output, corroborating with Ajah and Nmadu (2012) and Obasi et al. (2013) that an increase in area of farm land cultivated resulted in an increase in crop output.

The duration of farmer's membership in FBO was found to have coefficient of 0.210 , meaning that an increase of farmer membership in FBO by one year led to an increase in rice output by $21 \%$. This means that formation of FBO and its sustainability play a critical role in relation to increase farm productivity. Formation of FBOs enhances human capital; hence improve farmers' access to produce resources and efficiency levels. Adoption of integrated SWC techniques was found to have positive and statistically significant effect on rice output with a coefficient of 0.234 . This means adoption of an extra integrated SWC technique led to increase in output by 23.4\%. Similar results were found by Olarinde et al. (2012) and Abdul-Hanan et al. (2014). Furthermore, family labour was found to be positive and significant in relation to rice output with a coefficient of 0.007 , implying that a $100 \%$ increase in family labour will lead to an increase of $0.7 \%$ rice output.

However, extension visit was found to have a negative relation with output with a coefficient of -0.053. Meaning that farmers who received more extension visits had lower output. Extension agents act as intermediary persons between farmers and researchers for implementing 
government policies. They provide relevant information of government policy like inputs subsidy to farmers and also give feedback to the government for improvement of agricultural policies. Therefore, the less extension visit a farmer receives in a year, the less access they would likely have to government policies which could lead to a decline in crop output. Farmers who had contacts with extension agent frequently would have had the opportunity to be aware of fertilizer subsidy program. This will increase the intensity of fertilizer usage which will improves crop output. However, this present study could not establish why farmers who had more extension visits rather experienced lower yields.

Columns 3 and 4 in Table (3) present the results of the ESR model indicating the determinants of rice output differential between fertilizer subsidy beneficiaries and non-beneficiaries. The variables that were statistically significant in determining output for both regimes include farmer's age, sex, farm size, extension visit and seed. Education and duration of farmer membership in FBO was also significant for beneficiary farmers, while the adoption of integrated SWC practices also influenced the output of non-beneficiaries.

Table 3. Estimates of fertilizer subsidy effects and rice productivity equations

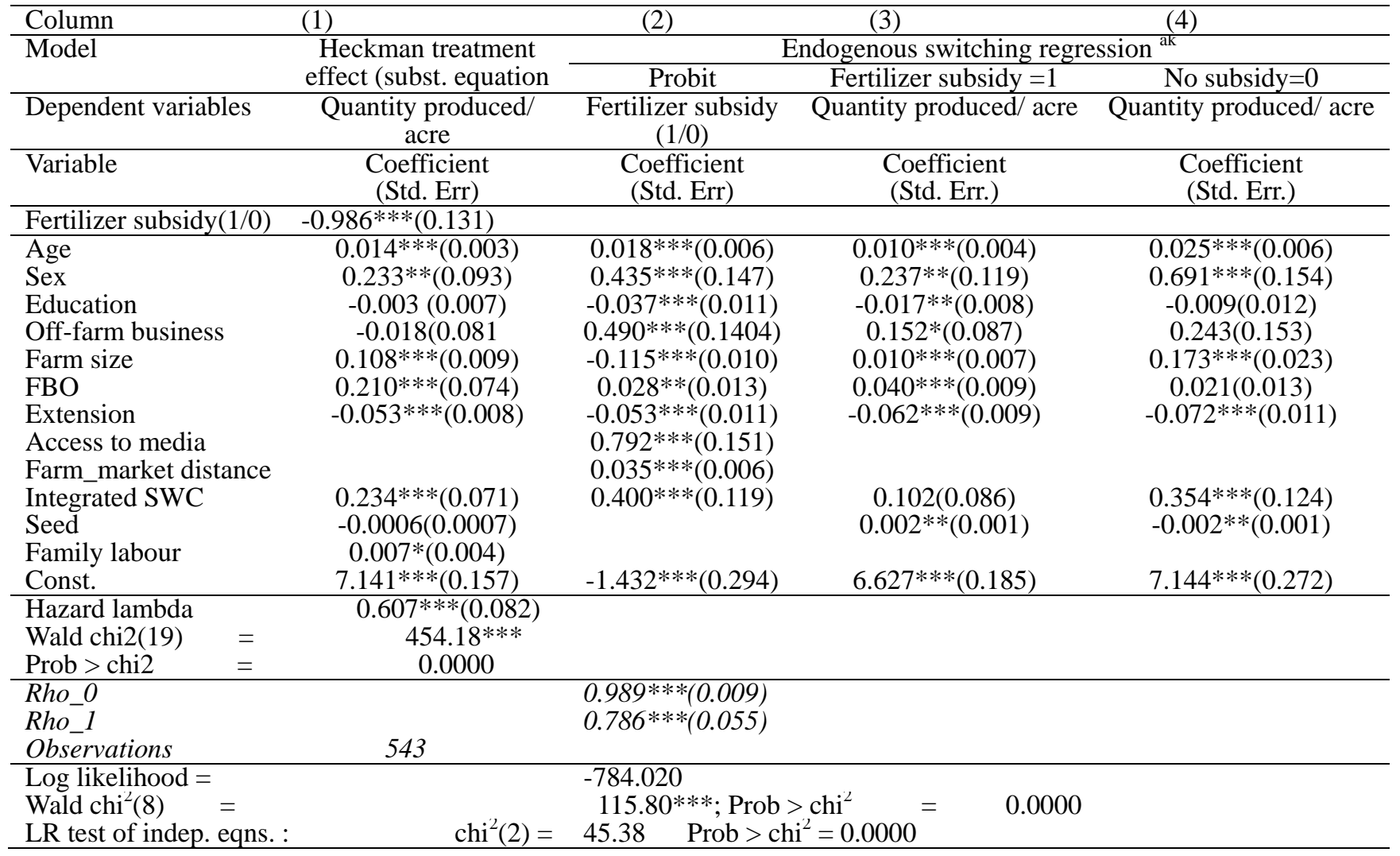

Notes: ak: Estimation by full information maximum likelihood by movestay command.

$* * *$ Significant at $1 \% ; * *$ significant at $5 \%$ and $*$ significant at $10 \%$.

Source: Authors' estimation (2018), using STATA 14 software

3.2.3 Average Treatment Effect of Fertilizer Subsidy on Rice Productivity 
The expected rice output for actual and counterfactual conditions among farmers who benefited from the fertilizer subsidy program and those who did not are shown in Table (4). The expected rice output (per hectare) for beneficiary farmers was about 7.89 bags $(678.88 \mathrm{~kg})$, while the output for non-beneficiary farmers was about $9.75 \mathrm{bags}(838.41 \mathrm{~kg})$. This implies that farmers who did not benefit had more output (an extra of $159.96 \mathrm{~kg}$ ) compared to their counterparts who benefited from the program. Nevertheless, the differences in output in favour of non-beneficiaries could be attributed to their skills, experience and resource endowment such as: wealth, agricultural land, livestock and other assets that generates investments.

The coefficient of treatment of fertilizer subsidy on the treated (TT) had negative sign. This means that non-beneficiaries achieved more rice output than the beneficiaries of the subsidy program, corroborating the results in the Heckman treatment effect model (see Table 3). In the counterfactual case (iii), farmers who benefited would have produced about 8.69 bags rice $(747.34 \mathrm{~kg})$ if they did not benefit. In the counterfactual case (iv) where a farmer who did not benefit had decided to benefit, they would have produced about 7.21 bags of rice $(620.06 \mathrm{~kg})$. The implication is that fertilizer subsidy policy decreased rice output, despite the aim of the policy to increase agricultural productivity within the period. The transitional heterogeneity (TH) effect was positive, meaning that the effect of the subsidy was greater for the farmers who actually did not benefit from the program compared to those who benefited.

Fertilizer subsidy program is an important social intervention to farmers (especially in developing countries) to improve farm productivity. The findings from the ESR diagnostic coefficients as well as the treatment effect models showed that there was an inverse relationship between the fertilizer subsidy program in the 2016/2017 production season and the output of rice. Fearon et al. (2015) also found in Ghana that fertilizer subsidy programs are largely ineffective and less efficient despite enormous budgetary allocation to such interventions. Also, Imoru and Ayamga (2015) conducted an empirical study on fertilizer subsidy effects on fertilizer use in the northern region of Ghana. Their findings showed that approximately $57 \%$ of farm households do not find fertilizer subsidy programs to improve fertilizer usage, and by extension, yield. Meanwhile the basis for fertilizer subsidy program is to increase agricultural output per hectare which is government's commitment to ensuring food security and improving the livelihoods of households in Ghana (Fearon et al., 2015). This could attribute to inadequate or poor policy implementation of fertilizer subsidy program as suggested by Kwao (2014).

It is also argued that in perfect competitive market situations, subsidies are not desirable as they resulted in inefficiencies and welfare losses in the conventional economic analysis (Crawford et al., 2006). According to Druilhe and Barreiro-Hurlé (2012), subsidy programs for that matter fertilizer subsidy program is believed to cause market distortions by encouraging abuse of fertilizer usage and smuggling. The major concerns some researchers like Fearon et al. (2015) have about fertilizer subsidies is how much of the subsidised farm inputs reach the intended target group as against how much ends up in wrong hands of Ghanaian who smuggle them across to Togo, and Burkina Faso. Rich people and those who are politically connected are said to have strong influence on the smuggling business that lead 
to market distortion and disconnecting the resource poor farm households in Ghana from accessing the inputs.

Table 4. Conditional expectations, treatment and heterogeneity effects

\begin{tabular}{|c|c|c|c|}
\hline \multirow[b]{2}{*}{ Sub-sample } & \multicolumn{2}{|c|}{ Decision stage } & \multirow[b]{2}{*}{ Treatment effect } \\
\hline & To benefit & Not to benefit & \\
\hline $\begin{array}{l}\text { Subsidy } \\
\text { beneficiaries }\end{array}$ & (a) $7.894(0.023)$ & (c) $8.691(0.028)$ & $\begin{array}{c}\mathrm{TT}=-1.485 * * * \\
(0.016)\end{array}$ \\
\hline Non-beneficiaries & (d) $7.206(0.017)$ & (b) $9.749(0.045)$ & $\begin{array}{c}\mathrm{TU}= \\
-1.855^{* * *(0.052)}\end{array}$ \\
\hline $\begin{array}{l}\text { Heterogeneity } \\
\text { effects }\end{array}$ & $\begin{array}{c}\mathrm{BH}_{1}=0.688 * * * \\
(0.006)\end{array}$ & $\begin{array}{c}\mathrm{BH}_{2}=-1.058 * * * \\
(0.017)\end{array}$ & $\mathrm{TH}=0.370 * * *(0.036)$ \\
\hline
\end{tabular}

*** Statistically significant at 1\%; Value in the brackets are standard errors

Note: 1 bag of rice $=86 \mathrm{~kg}(\mathrm{MoFA}$ conversion chart $)$

Source: Authors estimation using STATA (2018)

\section{Conclusions and Policy Implication}

This study investigated the determinants of participation in fertilizer subsidy programs, and rice productivity differences between beneficiaries and non-beneficiaries of fertilizer subsidy programs. FIML endogenous switching regression model was used for the estimation since it accounts for heterogeneity and unobserved characteristics of farmers. The findings indicated that farmers who did not benefit from fertilizer subsidy program had gained more output compared to their beneficiary counterparts. This finding suggests that fertilizer subsidy program and its delivery to farmers in Ghana should be enhanced and given both local and national attention. Adoption of integrated soil and water conservation (SWC) practices translates to more rice output for both fertilizer subsidy beneficiaries and non-beneficiaries, highlighting the complementarity in the adoption of SWC techniques and fertilizer subsidy. An integrated SWC program promotes participation in fertilizer subsidy program as it ensures efficient use and investment in SWC. The use of improved seed also leads to increased rice output. Therefore, farmers should be educated and encouraged to plant the right quantities of seeds to improve the food security situation in Ghana. To ensure value for money in crop production, guarantee greater efficiency and maximum reach to resource poor farmers, MoFA should work effectively with the government of Ghana and local district assemblies to restructure the fertilizer subsidy program by addressing the bottlenecks; while ensuring proper targeting.

\section{References}

Abdul-Hanan, A., Ayamga, M., \& Donkoh, S. A. (2014). Smallholder adoption of soil and water conservation techniques in Ghana. African Journal of Agricultural Research, 9(5), 539-546. https://doi.org/10.5897/AJAR2013.7952

Ajah, J., \& Nmadu, J. N. (2012). Small-scale maize farmers' access to farm inputs in Abuja, Nigeria. Kasetsart J. (Soc. Sci.), 33, 499-505. 
Anang, B. T. (2017). Effect of non-farm work on agricultural productivity: Empirical evidence from northern Ghana. WIDER Working Paper 2017/38.

Azumah, S. B., Donkoh, S. A., \& Awuni, J. A. (2018). The perceived effectiveness of agricultural technology transfer methods: Evidence from rice farmers in northern Ghana. Cogent Food \& Agriculture, 4, 1-11. https://doi.org/10.1080/23311932.2018.1503798

Azumah, S. B., Donkoh, S. A., \& Ehiakpor, D. S. (2016). Examining the determinants and effects of Contract Farming on Farm Income in the Northern Region of Ghana. Ghana Journal of Science, Technology and Development, 4(1), 1-10.

Benin, S., Jonhson, M., Abokyi, E., Ahorbo, G., Jimah, K., Nasser, G., ... Tenga, A. (2013). Revisiting Agricultural Input and Farm Support Subsidies in Africa: The Case of Ghana's Mechanisation", Fertilizer, Block Farms and Marketing Programs. International Food Policy Research Institute (IFPRI). Discussion Paper 01300. https://doi.org/10.2139/ssrn.2373185

Carter, D. W., \& Milon, J. W. (2005). Price Knowledge in Household Demand for Utility Services. Land Economics, 81(2), 265-283. https://doi.org/10.3368/le.81.2.265

Chibwana, C., Fisher, M., Jumbe, C., Masters, W., \& Shively, G. (2010). Measuring the impacts of Malawi's farm input subsidy program. Paper for discussion at BASIS AMA CRSP TC meeting. https://doi.org/10.2139/ssrn.1860867

Chirwa, E. W., Matita, M., \& Dorward, A. (2011). Factors Influencing Access to Agricultural Input Subsidy Coupons in Malawi. Future Agricultures Working paper 027, December 2011.

Crawford, E. W., Jayne, T. S, \& Valerie, A. K. (2006). Alternative Approaches for Promoting Fertilizer Use in Africa. Agriculture and Rural Development Discussion Paper 22, Washington D.C., the World Bank.

Di Falco, S., Veronesi, M., \& Yesuf, M. (2010). Does Adaption to Climate Change Provide Food Security? A Micro-Perspective from Ethiopia. American Journal of Agricultural Economics, 93(3), 829-846. https://doi.org/10.1093/ajae/aar006

Druilhe, Z., \& Barreiro-Hurlé, J. (2012). Fertilizer subsidies in sub-Saharan Africa. ESA Working Paper No. 12-04. Rome, FAO.

Fearon, J., Adraki, P. K., \& Boateng V. F. (2015). Fertilizer Subsidy Program in Ghana: Evidence of Performance after Six Years of Implementation. Journal of Biology, Agriculture and Healthcare, 5(21), 100-107.

Greene, W. H. (1993). Econometric Analysis. Second Edition. New York: Macmillan.

Heckman, J. (1974). Shadow prices, market wages, and labour supply. Econometrica, 42, 679- 694. https://doi.org/10.2307/1913937

Heckman, J. J. (1976). The common structure of statistical models of truncations, sample selection and limited dependent variables and a simple estimator for such models. Annals of Economic and Social Measurement, 5, 475-492. 
Heckman, J. J., Tobias, J. L., \& Vytlacil, E. J. (2001). Four parameters of interest in the evaluation of social programs. Southern Economic Journal, 68(2), 210-233. https://doi.org/10.2307/1061591

Imoru, J. A., \& Ayamga, M. (2015). Fertilizer subsidy effects on fertilizer use in the northern region of Ghana. African Journal of Agricultural Research, 10(53), 4926-4936. https://doi.org/10.5897/AJAR2015.10327

Kwao, P. (2014). Procurement challenges in the implementation of fertilizer Subsidy program in Ashanti region. Doctoral Dissertation. Kwame Nkrumah University of Science and Technology; Kumasi, Ghana.

Liverpool-Tasie, L. S. O. (2012). Targeted Subsidies and Private Market Participation: An Assessment of fertilizer demand in Nigeria. IFPRI Discussion Paper, 01194.

Lokshin, M., \& Sajaia, Z. (2004). Maximum likelihood estimation of endogenous switching regression models. STATA Journal, 282-289. https://doi.org/10.1177/1536867X0400400306

Maddala, G. S. (1983). Limited-dependent and qualitative variables in economics. New York, NY: Cambridge University Press. https://doi.org/10.1017/CBO9780511810176

Martey, E., Wiredu, A. N, Etwire, P. M., Fosu, M., Buah. S.S.J, Bidzakin, J., Ahiabor, B.D.K., \& Kusi, F. (2013). Fertiliser Adoption and Use Intensity among Smallholder Farmers in Northern Ghana: A Case Study of the AGRA Soil Health Project. Sustain. Agric. Res., 3(1), 24. https://doi.org/10.5539/sar.v3n1p24

Ministry of Food and Agriculture (MoFA) (2015). Status and Impact of Ghana's Fertilizer Subsidy Program, Policy Brief'. Accra: Ghana. www.csir-stepri.org.

Ministry of Food and Agriculture (MoFA) (2016). Facts and Figures (2015). Statistics, Research and Information Directorate (SRID), October, 2016

Ministry of Food and Agriculture (MoFA) (2017). National fertilizer subsidy program for 2017 information to stakeholders, Accra, Ghana.

Ministry of Food and Agriculture (MoFA), (2011). Evaluation of Four Special Initiatives of the Ministry of Food and Agriculture. Government of Ghana. A Draft Report, 8th November 2011.

Nonvide, G. M. A. (2018). A re-examination of the impact of irrigation on rice production in Benin: An application of the endogenous switching model. Kasetsart Journal of Social Sciences $x x x, 1-6$. https://doi.org/10.1016/j.kjss.2017.12.020

Obasi, P. C., Ukoha, A. H., Ukewuihe, I. S., \& Chidiebere-Mark, N. M. (2013). Factors Affecting Agricultural Productivity among Arable Crop Farmers in Imo State, Nigeria. American Journal of Experimental Agriculture, 3(2), 443-454. https://doi.org/10.9734/AJEA/2013/2030

Ogheneruemu, O. E., \& Abdul-Hameed, B. O. (2017). Determinants of participation in 
fertilizer subsidy program among rice farmers in Ogun State, Nigeria. Journal of Development and Agricultural Economics, 9(6), 162-167.

Olarinde, L. O., Oduol, J. B., Binam, J. N., Diagne, A., Njuki, J., \& Adekunl A. A. (2012). Impact of the Adoption of Soil and Water Conservation Practices on Crop Production: Baseline Evidence of the Sub Saharan Africa Challenge Program. American-Eurasian J. Agric. \& Environ. Sci., 12(3), 293-305.

Oya, K. (2005). Properties of estimators of count data model with endogenous switching. Mathematics and Computers in Simulation, 68(5-6), 536-544.

https://doi.org/10.1016/j.matcom.2005.02.011

Ragasa, C., \& Chapoto, A. (2017). Moving in the right direction? The role of price subsidies in fertilizer use and maize productivity in Ghana", Food Security, 9(2), 329-353. https://doi.org/10.1007/s12571-017-0661-7

Ricker-Gilbert, J., \&Jayne, T. S. (2008). The Impact of Fertilizer Subsidies on National Fertilizer Use: An Example from Malawi. Paper presented at the American Agricultural Economics Association Annual Meeting, Orlando, FL.

Seck, A. (2016). Fertilizer Subsidy and Agricultural Productivity in Senegal. AGRODEP Working Paper 0024, April 2016.

Sinyolo, S., Mudhara, M., \& Wale, E. (2014). The impact of smallholder irrigation on household welfare: The case of Tugela Ferry irrigation scheme in KwaZulu-Natal, South Africa. Water SA, 40(1), 145-156. https://doi.org/10.4314/wsa.v40i1.18

STATA Software. Version 14. https://www.stata.com

Terza, J. V. (1998). Estimating count data models with endogenous switching: Sample selection and endogenous treatment effects. Journal of econometrics, 84(1), 129-154.

https://doi.org/10.1016/S0304-4076(97)00082-1

Toenniessenn, G., Adesina, A., \& DeVries, J. (2008). Building an Alliance for a Green Revolution in Africa. Annals of the New York. Acad. Sci., 1136, 233-242.

https://doi.org/10.1196/annals.1425.028

Vondolia, G. K., Eggert, H., \& Stage, J. (2012). Nudging Boserup? The Impact of Fertilizer Subsidies on Investment in Soil and Water Conservation. Discussion Paper Series, June 2012, Environment for Development, (EfD) DP 12-08. Washington, DC.

World Bank (2014). Fertilizer Consumption (kilograms per hectare of arable land), Food and Agricultural Organization 2014.

Zackaria, A., Ansah, I. K., Abdulai, S., \& Donkoh, S. A. (2016). The Determinants and Effects of Jica Rice Technology Adoption in the Sagnarigu District of the Northern Region, Ghana. UDS International Journal of Development, 3(1), 1-12.

Zhou, Y., Mosler, H., \& Abbaspour K. C. (2010). Factors affecting farmers' decisions on fertilizer use: A case study for the Chaobai watershed in Northern China. Journal of 


\section{Macrothink}

Sustainable Development, 4(1), 80-102. 2019, Vol. 7, No. 1

\section{Glossary}

FBO Farmer-Based Organisation

MoFA Ministry of Food and Agriculture

SWC Soil and Water Conservation

\section{Copyright Disclaimer}

Copyright for this article is retained by the author(s), with first publication rights granted to the journal.

This is an open-access article distributed under the terms and conditions of the Creative Commons Attribution license (http://creativecommons.org/licenses/by/4.0/). 